This item was submitted to Loughborough's Research Repository by the author.

Items in Figshare are protected by copyright, with all rights reserved, unless otherwise indicated.

\title{
Compact UWB bandpass filter with reconfigurable notched band
}

PLEASE CITE THE PUBLISHED VERSION

http://dx.doi.org/10.1049/el.2012.3555

\section{PUBLISHER}

(c) Institution of Engineering and Technology

\section{VERSION}

AM (Accepted Manuscript)

\section{PUBLISHER STATEMENT}

This work is made available according to the conditions of the Creative Commons Attribution-NonCommercialNoDerivatives 4.0 International (CC BY-NC-ND 4.0) licence. Full details of this licence are available at: https://creativecommons.org/licenses/by-nc-nd/4.0/

\section{LICENCE}

CC BY-NC-ND 4.0

\section{REPOSITORY RECORD}

Rabbi, K., L. Athukorala, C.J. Panagamuwa, J.C. Vardaxoglou, and D. Budimir. 2019. "Compact UWB Bandpass Filter with Reconfigurable Notched Band”. figshare. https://hdl.handle.net/2134/22678. 


\section{Compact UWB Bandpass Filter with Reconfigurable Notched Band}

\author{
K. Rabbi, L. Athukorala, C. Panagamuwa, J. C. Vardaxoglou \\ and D. Budimir
}

A compact bandpass filter is presented for ultra-wideband (UWB) applications with a reconfigurable notched band to reject unwanted signals from the WiMAX systems. A single PIN diode is used for the purpose of switching the notch. An optical switch, comprised of a silicon dice activated using near infrared light is also investigated as an alternative to the PIN diode. While the switch is in the ON state this reconfigurable filter behaves as a bandpass filter with a notch at 3.5 $\mathrm{GHz}$ and a full band response is obtained in the OFF state. The filter offers excellent performance for lower-band frequency of UWB system, ranging from 3.1 to $5.0 \mathrm{GHz}$ and exhibits very low pass-band insertion loss. Also transmission zeros are generated at the passband edges to enhance the signal selectivity. A filter sample is designed and fabricated to provide experimental verification on the proposed filter. A good agreement has been achieved between simulated and measured results with both the PIN diode as well as the optical switch. The proposed reconfigurable filter with notched band was able to achieve $40 \%$ size reduction as compared to an embedded open-circuited stub.

Introduction: Ultra-wideband (UWB) systems have aroused a great deal of attention and a number of UWB bandpass filter design techniques have been proposed in the past year such as the multi-mode resonators (MMR) [1-2], multilayer aperture-coupled patches [3] in order to achieve compactness but suffered from poor attenuation poles between passband edges. On the other hand, UWB communication spectrum covers a very wide frequency band and is overlapped with WiMAX (3.5 $\mathrm{GHz})$ in the lower band and with WLAN $(5.8 \mathrm{GHz})$ in the upper band. These services potentially interfere with UWB signals and therefore may cause signal distortion. One of the possible and effective solutions for this problem is to realize narrow rejection bands within the passband of a UWB bandpass filter. The reason tends to focus on reconfigurable notch features in order to avoid the possibility of interference on the increasingly crowded spectrum and achieve multi-functionality using a single filter. Several UWB bandpass filters with notch bands have been reported [4-6].

In this paper, we present a compact UWB filter with a reconfigurable notched band. Two identical filters were fabricated, where one was tested using a PIN switch as it offers high power handling capability, quick switching speed with reduced cost, easier packaging and a lower bias voltage. Conversely, the other employed with an optical switch which offers high power handling capability, immunity to electromagnetic interference, excellent isolation between the microwave and switch control circuits and very low distortion [7]. Both filters have little loss, significantly low distortion and high switching speed. Simulation and experimental results have been presented to validate the argument.

Initial UWB Bandpass Filter Design: The proposed filter as shown in Fig. 1 is a third-order bandpass filter composed of 'a single $\lambda_{g} / 2$ ' resonator, which is placed initially between 'a pair of $\lambda_{g} / 4$ ' short circuited resonators. To sharpen the out-of-band rejection skirt, the shunt short-circuited stubs are stretched by two times, i.e., from ' $\lambda_{g} / 4$ to $\lambda_{g} / 2^{\prime}$ which turns the section from short to open-circuited stub and as shown in Fig. $2 a$ which contributes two attenuation poles on each side of the passband and simulated results are presented in Fig. $2 b$.

Equivalence of the 'two input admittance $\mathrm{Y}_{\text {in1 }}$ and $\mathrm{Y}_{\text {in2 }}$ ' in Fig. $2 a$ can be expressed by 'the below equation (1) with an assumption $\mathrm{Y}_{\mathrm{ia}}=\mathrm{X}_{\mathrm{i}} \mathrm{Y}_{\mathrm{ib}}$ ',

$$
\begin{aligned}
& Y_{i a}=\frac{Y_{i}\left(X \tan ^{2} \theta-1\right)}{\left(1+X_{i}\right)^{2} \tan ^{2} \theta} \\
& X_{i}=\cot ^{2}\left(\frac{\Pi}{2} \frac{\infty}{\omega_{0}}\right) \quad \omega_{\infty} / \omega_{0}<\omega / \omega_{0}
\end{aligned}
$$
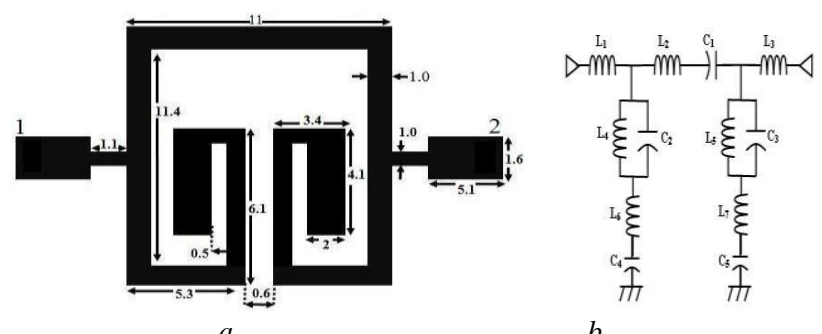

Fig. 1 Schematic layout (dimensions in $\mathrm{mm}$ in Fig. 1a), Equivalent circuit of the proposed UWB bandpass filter $\left(\mathrm{L}_{1}=\mathrm{L}_{3}=0.2 \mathrm{nH}, \mathrm{L}_{2}=5.6 \mathrm{nH}\right.$, $\mathrm{L}_{4}=\mathrm{L}_{5}=0.403 \mathrm{nH}, \mathrm{L}_{6}=0.524 \mathrm{nH}, \mathrm{L}_{7}=0.202 \mathrm{nH}, \mathrm{C}_{1}=0.322 \mathrm{pF}, \mathrm{C}_{2}=\mathrm{C}_{3}=4.5 \mathrm{pF}$, $\left.\mathrm{C}_{4}=8.4 \mathrm{pF}, \mathrm{C}_{5}=6.0 \mathrm{pF}\right)($ Fig. 1 b).

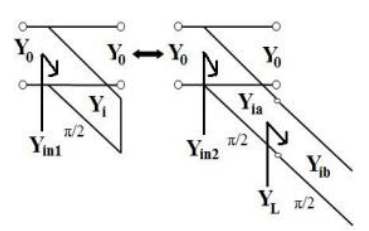

$a$

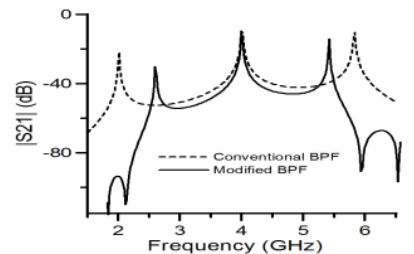

$b$
Fig. 2 Transmission line model of short to open-circuited stub configuration (Fig. 2a), Comparison between conventional and modified BPF (Fig. 2b).

where ' $\theta=\pi \omega / 2 \omega_{0}$ ' and ' $\omega_{\infty}$ is a frequency' at which the shunt lines present short circuit to the main transmission line and cause infinite attenuation.

Proposed UWB filter with notch structure: To reject the undesired WiMAX signal at $3.5 \mathrm{GHz}$, a section of L-shaped parallel coupled transmission line with a grounded end is added as illustrated in Fig $3 a$. The electrical length of the stub is chosen to be $90^{\circ}$ at $3.5 \mathrm{GHz}$ in order to create a transmission zero at this frequency as coupled lines coupling maximize at ' $\beta 1=\lambda_{\mathrm{g}} / 4$ '. The switch is placed as shown in Fig $3 b$. When the switch (either pin diode or optical switch) is in the on state, the joined section length is equivalent to ' $\lambda_{\mathrm{g}} / 4$ ' and it reaches at maximum coupling stage which contributes a narrow reject band within the filter passband at $3.5 \mathrm{GHz}$. Conversely, in the off state, there is no connection between the open-stub and the L-shaped section provides full passband response due to low coupling between two coupled lines.

The 'coupling coefficient $\mathrm{C}(2)$ ' in Fig. $3 a$ is defined as,

$C=\left(Z_{0 e}-Z_{00}\right) /\left(Z_{0 e}+Z_{00}\right)$

The 'resonant frequency $f_{r}$ in (3)' is given by,

$$
f_{r}=\frac{1}{2 \pi \sqrt{L\left(C_{e}+C_{o}\right)}}
$$

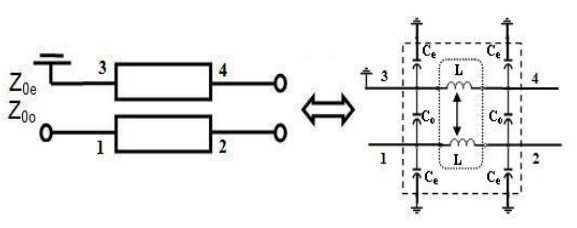

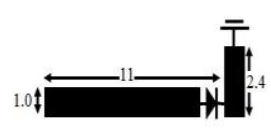

$b$
Fig. 3 Notch structure.

a Notch equivalent circuit.

b Notch layout

Switching elements: The $0.3 \mathrm{~mm}$ gap is overlaid with a PIN diode switch (BAP65-02) as shown above in Fig. $3 b$ in one filter circuit and the other is overlaid with a 1 x $3 \mathrm{~mm}$ silicon dice. The PIN diode was modelled by using a capacitor of value $0.8 \mathrm{pF}$ in the OFF state and a resistor value of $0.9 \Omega$ in the $\mathrm{ON}$ state [7]. The silicon wafer has a 
conductivity of $16.7 \mathrm{mS} / \mathrm{m}$ in the dark which increases to $150 \mathrm{~S} / \mathrm{m}$ when illuminated by $200 \mathrm{~mW}$ of $980 \mathrm{~nm}$ wavelength laser light [7].

Simulated and measured results: To validate the circuit concept, the filter is designed and fabricated on Taconic RF35 substrate with ' $\varepsilon_{\mathrm{r}}=$ 3.5 ' and ' $\mathrm{h}=0.76 \mathrm{~mm}$ ' and tested with a pin/optical switch as shown in Fig. 4. The overall filter dimension is approximately ' $0.25 \lambda_{\mathrm{g}} \mathrm{x} 0.23 \lambda_{\mathrm{g}}$ ', where ' $\lambda \mathrm{g}$ is the microstrip guided wavelength' on the substrate at centre frequency. The full wave simulated S-parameters of the filter with pin diode in ON \& OFF states with the corresponding measurements, were taken with Agilent vector network analyzer E38361A while filter with the optical switch were measured using an Anritsu Lightning 37397D Vector Network Analyzer.

In the switchable notched band case with pin diode, the notched band centered at $3.52 \mathrm{GHz}$ has $5-\mathrm{dB}$ rejection fractional bandwidth of about $3.2 \%$ and the attenuation at the centre of the notched band is around 16 $\mathrm{dB}$, also measured minimum insertion loss of $0.7 \mathrm{~dB}$ as shown in Fig. $4 a$. In contrast, using optical switch, the notch rejections were observed at $3.54 \mathrm{GHz}$ at approximately $12 \mathrm{~dB}$ and passband insertion-loss of the bandpass filter was $1.0 \mathrm{~dB}$ as illustrated in Fig. $4 b$. A photograph of the fabricated filter is shown in Fig. 4c. Moreover, the filter has a flat group delay within the passband of about $0.2-0.35 \mathrm{~ns}$ in both cases. The small discrepancies between the simulated and measured responses may be attributed to the various fabrication errors involved and the poor conductivity of the switches especially for optical switch.

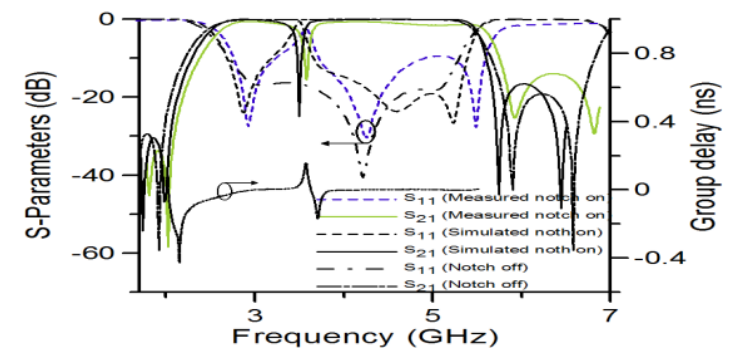

$a$

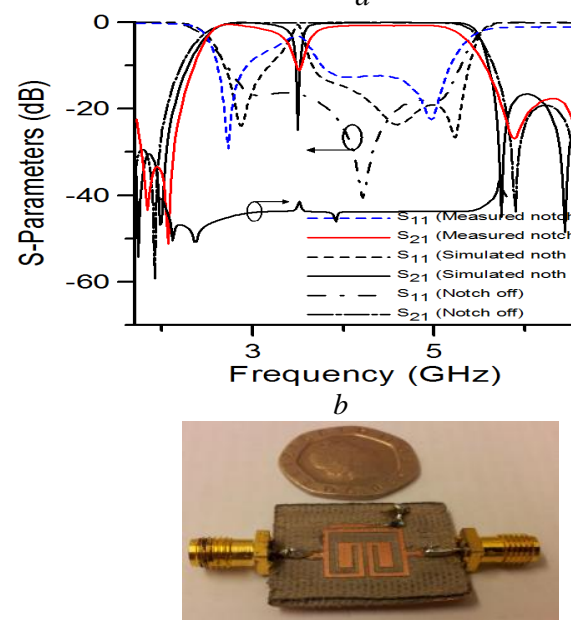

$c$

Fig. 4 Simulated and measured results.

a with pin diode.

$b$ with optical switch

c Photograph of the fabricated UWB filter

Conclusion: A microstrip filter with a reconfigurable notched band has been presented. A single pin diode and an optical switch have been used to reconfigure the notch at $3.5 \mathrm{GHz}$ within the passbands of the UWB filter. In this experiment, the proposed filter has shown good agreement with simulations. Also, promising features of optical switches have been shown as an alternative to the pin diode. In addition, this filter has the merit of compact size and easier fabrication. The obtained results indicate that the proposed reconfigurable filter is promising for modern UWB systems solving the problem of WiMAX interferences allocated in the UWB spectrum.
K. Rabbi, L. Athukorala and D. Budimir (Wireless Communication Research Group, University of Westminster, London, W1W 6UW, UK) E-mail: d.budimir@wmin.ac.uk

C. Panagamuwa, J. C. Vardaxoglou (Wireless Communication Research Group, Loughborough University, Loughborough, UK)

\section{References}

1 L. Zhu, S. Sun, and W. Menzel, "Ultra-wideband (UWB) bandpass filter using multiple-mode resonator," IEEE Microw. Wireless Compon. Lett., vol. 15, no. 11, pp. 796-798, Nov. 2005.

2 J. Gao, L. Zhu, W. Menzel, and F. Bögelsack, "Short-circuited CPW multiple-mode resonator for ultra-wideband (UWB) bandpass filter," IEEE Microw. Wireless Compon. Lett., vol. 16, no. 3, pp. 104-106, Mar. 2006.

3 A. M. Abbosh, "Planar bandpass filters for ultra-wideband applications," IEEE Trans. Microw. Theory Tech., vol. 55, no. 10, pp. 2262-2269, Oct. 2007.

4 G. M. Yang R. Jin, C. Vittoria, V. G. Harris, and N. X. Sun,'Small ultra-wideband (UWB) bandpass filter with notched band", IEEE Microw. Wirel. Compon. Lett., vol.18, pp. 176-178, 2008.

5 S. W. Wong, and L. Zhu,'Implementation of compact UWB bandpass filter with a notch-band", IEEE Microw. Wirel. Compon. Lett., vol.18, pp. 10-12, 2008.

6 H. Shaman, and J. S. Hong "Ultra-wideband (UWB) bandpass filter with embedded band notch structures", IEEE Microw. Wireless Compon. Lett., vol.17, pp. 193-195, 2007.

7 K. Rabbi, L. Athukorala, C. Panagamuwa, J. C. Vardaxoglou, and D. Budimir, "High-Linearity Reconfigurable Microstrip UWB Bandpass Filters", $6^{\text {th }}$ European Microwave Integrated Circuits Conference (EuMIC), pp. 172-175, Manchester, UK, October 2011. 